\title{
Brotes que no quieren marchitar. El movimiento de ferias y las políticas para la agricultura familiar en Argentina (2015-2018)
}

\author{
Cristian Emanuel Jara \\ Universidad de Santiago del Estero (UNSE) \\ Instituto de Estudios para el Desarrollo Social (INDES-CONICET) \\ Santiago del Estero. Argentina \\ Email: cristianjara_cl@hotmail.com
}

\begin{abstract}
Resumen: El desarrollo de las ferias de la agricultura familiar tiene continuidad y muestra una tendencia expansiva en América Latina. Este artículo se pregunta: ¿Cómo se dio el proceso de organización y disputa de las políticas públicas que resultó en la construcción de estas ferias en Santiago del Estero (noroeste argentino)? ¿Cuáles son sus fortalezas y sus debilidades en un contexto de reducción del apoyo por parte del Estado entre 2015-2018? Aunque algunas de las experiencias registradas puedan resultar pequeñas y aisladas, otras van ampliando sus dimensiones. Es decir, que emergen como brotes de un modelo de desarrollo rural en construcción que se resisten a marchitar. Las potencialidades de las ferias se expresan en aspectos que trascienden lo económicos: a la vez que promueven la diversificación y la generación de un ingreso alternativo, son una expresión de las luchas políticas cotidianas que actualmente caracterizan al campo.
\end{abstract} Estero.

Palabras claves: ferias de la agricultura familiar; sociología de los procesos emergentes; interfaces; Santiago del

\section{Outbreaks that don't want to wilt. The fair movement and policies for family agriculture in Argentina (2015-2018)}

\begin{abstract}
The development of the family agriculture fairs is continous and shows an expansive tendency in Latin America. This article wonders: How did the process of organization and dispute of public policies that resulted in the construction of these fairs in Santiago del Estero (northwestern Argentina) take place? What are their strengths and weaknesses in a context of reduced support by the State between 2015-2018? Although some of the experiences recorded may be small and isolated, others are growing in size. In other words, they are emerging as outbreaks of a rural development model under construction that are resistant to wilt. The potential of the fairs is expressed in aspects that transcend the economic: while they promote diversification and the generation of an alternative income, they are an expression of the daily political struggles that currently characterize the countryside.
\end{abstract}

Keywords: family agriculture fairs; sociology of emerging processes; interfaces; Santiago del Estero.

\section{Brotos que não querem murchar. $\mathbf{O}$ movimento de feiras e as políticas para a agricultura familiar na Argentina (2015-2018)}

Resumo: O desenvolvimento das feiras de agricultura familiar tem continuidade e mostra uma tendência expansiva na América Latina. Este artigo pergunta-se: como foi o processo de organização e disputa de políticas públicas que resultou na construção dessas feiras em Santiago del Estero (noroeste da Argentina)? Quais são seus pontos fortes e fracos em um contexto de apoio reduzido do Estado entre 2015-2018? Embora algumas das experiências registradas possam ser pequenas e isoladas, outras expandem suas dimensões. Ou seja, surgem como brotos de um modelo de desenvolvimento rural em construção que se recusa a definhar. As potencialidades das feiras se expressam em aspectos que transcendem o econômico: 
enquanto promovem a diversificação e a geração de uma renda alternativa, são uma expressão das lutas políticas cotidianas que atualmente caracterizam o campo.

Palavras-chave: feiras de agricultura familiar; sociologia dos processos emergentes; interfaces; Santiago del Estero.

\section{Introducción}

En la última década, el aumento de los precios de los alimentos puso bajo amenaza la sostenibilidad de la seguridad alimentaria global. De hecho, el desarrollo del sector agrícola estuvo caracterizado por una marcada volatilidad en los precios internacionales de los principales productos básicos, agravado también por sequías, inundaciones y temperaturas extremas relacionadas con el cambio climático (Mc Michael, 2013).

En Argentina, las políticas agrarias que aplicó Mauricio Macri entre 2015-2018 agudizaron la crisis alimentaria ${ }^{1}$, a pesar de que el país tiene capacidad suficiente para alimentar a 10 veces su población ${ }^{2}$. Según un informe del Consejo de Derechos Humanos de la ONU, el 60\% de la tierra cultivada (19 millones de hectáreas) está dedicada a la producción de soja y la mayor parte se exporta. Así, solamente un 2\% de esta oleaginosa se consume en el país y el resto tiene como destino el mercado internacional (Elver, 2019). A su vez, la FAO (2018) destaca que la inseguridad alimentaria severa aumentó del 5,8\% (2.500.000 personas) en el período 2014-2016 a 8,7\% (3.800.000 personas) en el período 2015-2017.

En este escenario, el artículo abordará el papel de las ferias como estrategias de comercialización de alimentos, desplegadas por agricultores familiares frente a la crisis económica que atraviesa el país. Estas estrategias consisten en circuitos cortos que permiten no solo aumentar la rentabilidad por la reducción de intermediarios y por el agregado de valor, sino que a su vez ofrecen productos frescos y de mayor calidad al consumidor (Rodríguez Sperat, Paz, Suárez y Díaz, 2015).

El estudio se realiza en el noroeste argentino (ver mapa 1), más precisamente en Santiago del Estero, durante el periodo 2015- 2018. El recorte temporal resulta significativo para analizar la continuidad y la resistencia a desaparecer de las ferias que, habiendo surgido por iniciativa gubernamental en años anteriores, en el último tiempo sufrieron la pérdida del apoyo de las políticas públicas nacionales.

Por otro lado, el anclaje de esta investigación en Santiago del Estero resulta significativo dado que su estructura agraria se destaca por la presencia mayoritaria de la agricultura familiar, cercana al 80\%, es decir 17 mil explotaciones agropecuarias aproximadamente (Paz, de Dios y Gutiérrez, 2014). En este territorio, las ferias siguieron procesos muy diferentes a los ocurridos en otras regiones. Mientras que las experiencias más estudiadas de ferias en Argentina se desarrollaron en el noroeste del país durante la década de 1990, como una reacción a la crisis de la economía regional provocada por la caída de los precios de los cultivos industriales y las medidas neoliberales del menemismo (Rodríguez, 2010; Caballero 2010), la expansión de estos sistemas de mercadeo en Santiago del Estero es posterior y se sitúa en el marco de las políticas públicas nacionales de promoción de la agricultura familiar, especialmente desde 2006- $2015^{3}$, que permitieron la conformación de grupos de feriantes y el acceso a recursos del Estado.

El artículo se pregunta: ¿Cómo se dio el proceso de organización y disputa de las políticas públicas que resultó en la construcción de ferias de la agricultura familiar? ¿Cuáles son sus fortalezas y sus debilidades en un contexto de reducción del apoyo por parte del Estado?

La hipótesis es que el movimiento de ferias de la agricultura familiar puede ser enmarcado en un repertorio de luchas y formas de organización diseminadas en el espacio rural que representan semillas o brotes emergentes por medio de las cuales los agricultores familiares de base campesina intentan mejorar la calidad de vida (Schneider et al, 2014).

La metáfora de las semillas y los brotes, en relación con las experiencias de ferias, alude a un conjunto de 
dispositivos, no siempre deliberados, que los agricultores están construyendo para hacer o pensar «las cosas de un modo diferente». En otros términos, representan novedades, rupturas con la rutina (Wiskerke, 2004)4. Tales iniciativas (embrionarias, incompletas y abiertas) son la expresión de formas alter-nativas de comercialización construidas para hacer frente a los históricos problemas de precariedad que enfrentan los pequeños productores (De Sousa Santos y Rodríguez, 2011).

En este trabajo se identificaron once ferias permanentes de la agricultura familiar en la provincia. Aunque algunas de las experiencias registradas puedan resultar pequeñas y aisladas entre sí, otras van ampliando sus dimensiones. Es decir, siguen trayectorias diversas: mientras algunas todavía son semillas, otras emergen como brotes (Schneider et al, 2014).

Por otro lado, las formas de intervención estatal condicionan significativamente el funcionamiento de las mismas debido a la carencia de financiamiento alternativo que resulte suficiente. En efecto, la dependencia de las políticas públicas dificulta su pervivencia en el tiempo y hace necesario fortalecer sus márgenes de autonomía para trascender el contingente impulso gubernamental (García y Fontanet, 2018).

A partir de una hermenéutica de la emergencia (De Sousa Santos y Rodríguez, 2011) se buscará visibilizar la dimensión propositiva que surge desde las mismas experiencias de feriar. Sin dar por supuesto el carácter emancipador, esto desafía al investigador social a la reconstrucción de los procesos de una forma rigurosa para comprenderlos en sus potencialidades y en sus limitaciones (De la Garza, 2001).

En este sentido, compartimos el desafío que plantea Enrique de la Garza (2001) sobre la necesidad de que la investigación sobre el cambio social no solo debe dar cuenta de lo dado, sino de lo dado-dándose. Por lo tanto, la teoría social debería explorar las oportunidades que se abren o se cierran y cómo son percibidas por los sujetos. ${ }^{5}$

El artículo está estructurado de la siguiente forma: en primer lugar, se explica el proceso de construcción del objeto de estudio y el marco conceptual desde donde se parte. Seguidamente, se detalla el diseño metodológico del estudio. En tercer lugar, se realiza una descripción de las ferias de la agricultura familiar en Santiago del Estero. Finalmente, se identifican, a partir del trabajo de campo, los obstáculos y potencialidades que contienen las experiencias en marcha.

\section{Marco referencial y consideraciones metodológicas}

No se puede disociar el método de las elecciones teóricas asociadas a él. Por ende, se consideró pertinente explicitar algunos posicionamientos al respecto. Se parte de la perspectiva de una sociología de los actores y de los procesos emergentes que considera fundamental ir más allá de la denuncia al modelo agropecuario dominante que margina a los agricultores familiares. El desafío cognitivo está encauzado a conocer cómo los agricultores se organizan y pueden diseñar alternativas de desarrollo rural (Schneider y Menezes, 2014).

En esta dirección, se adopta un enfoque que valora el papel activo de los actores en los procesos de cambio social, lo cual está inspirado en la escuela de Wageningen, especialmente Norman Long (2007), quien propone una perspectiva orientada a los actores (POA) para comprender el modo en que éstos interactúan, creando interfaces ${ }^{6}$.

Desde esta óptica, los actores sociales (individuales o colectivos) están dotados de poder de agencia, lo que implica reconocer la capacidad de acción de acuerdo a determinados proyectos. De este modo, se accionan reciprocidades (amistad, compadreo y vecindad), obligaciones morales y jerarquía. Dichas relaciones involucran una serie de normas, valores y arreglos explícitos e implícitos (Schneider y Menezes, 2014).

Conforme a ello, las ferias son analizadas en tres niveles de análisis. En primer término, las ferias en las interfaces de las políticas de desarrollo rural y las organizaciones sociales. Los encuentros en estas interfaces son a menudo decisivos para el éxito o el fracaso de los mercados emergentes. En segundo lugar, se considera 
a las ferias como lugares concretos de comercialización. Esto implica tomar distancia de la concesión neoclásica que considera al mercado como un sistema abstracto que se regula a sí mismo (Hebinck, Schneider y Van Der Ploeg, 2015). Finalmente, las ferias son consideradas como un territorio específico. Es decir, un fragmento espacial apropiado y construido colectivamente, a partir de valores diferentes al modelo del agronegocio (Fernándes, 2009). En otras palabras, las ferias constituyen un foco de resistencia y reinvención de la agricultura familiar.

La elección de este referencial teórico no fue pensada como una construcción a priori de definiciones abstractas (Carvalho et al 2014). Si bien el diseño metodológico implicó un momento deductivo, apoyado en la reflexión teórica, el propósito fue esbozar una mirada sobre los problemas concretos de la realidad rural santiagueña, tomando como punto de partida hipotético, la idea de que las ferias constituirían «Semillas y Brotes» de una nueva forma de desarrollo rural. De este modo, la teoría es concebida como un andamiaje. Es decir, una construcción provisoria que actúa como referencia en la investigación empírica propuesta. Así, lo deductivo y lo inductivo (la observación empírica), formaron parte de un mismo proceso dialéctico.

En este orden lógico, se utilizó un estudio de caso múltiple, el cual consistió en examinar detalladamente un grupo de unidades seleccionadas que se muestran relevantes frente al tema de investigación. En otros términos, no se buscó la representatividad estadística, sino la significatividad (Vasilachis, 2006). La selección de los casos tuvo en cuenta los siguientes criterios: a) se trata de ferias que son gestionadas por productores de la agricultura familiar; b) se establecen relaciones directas entre productores y consumidores, sin intermediaciones; y c) se realizan como mínimo una vez por mes (Golsberg, 2010).

La construcción de los datos conllevó la triangulación de técnicas que engloban el análisis documental, la observación directa y entrevistas semiestructuradas a técnicos y feriantes. Lo cual fue complementado con fuentes secundarias de datos, tales como registros proporcionados por técnicos de la Subsecretaría de Agricultura Familiar de la Nación.

Para el análisis, se elaboró una matriz que facilitó la clasificación y codificación de la información que valora tanto al actor (con sus prácticas, saberes e identidades), como al contexto en el que actúa. En efecto, se identificaron las siguientes dimensiones:

a) Situación actual de la feria: Cantidad de feriantes, localización, frecuencia, tipos de productos y la estimación de clientes por jornadas.

b) Trayectoria de la feria: Cuándo se inició, quienes intervinieron y con qué recursos. ¿Qué razones llevaron a iniciar la actividad? ¿La feria fue incentivada por alguna política pública? ¿Qué cambios hubo durante el periodo 2015-2018?

c) Dispositivo organizativo: ¿Cómo se realiza el intercambio? ¿Existen reglamentos? ¿Cuáles son los derechos y obligaciones de los feriantes?

d) Resultados: ¿Hubo mejoras en los ingresos de las familias? ¿Aparecieron actividades que no existían anteriormente?

e) Obstáculos: ¿Qué aspectos generaron tensiones en la organización de la feria? ¿En un contexto de ajuste fiscal, se puede prever que la feria tenga continuidad independientemente de la reducción del apoyo por parte de las políticas públicas?

En suma, el marco referencial y la estrategia metodológica estuvieron orientados a reconstruir los dispositivos organizativos en torno a estos lugares específicos de interacción social para comercializar y disputar los recursos del Estado.

\section{Caracterización de las Ferias de la Agricultura Familiar en Santiago del Estero}

La provincia de Santiago del Estero está ubicada en el noroeste de Argentina (ver Mapa 1), con un área de 136.351 kilómetros cuadrados. Según el último Censo Nacional Población (Argentina, 2010), la provincia tiene 874.006 habitantes. El 31.3\% de la población está clasificada como rural y es la proporción más alta del país?. A 
su vez, el Registro Nacional de la Agricultura Familiar (RENAF) reconoció 17.453 explotaciones de agricultores familiares, lo cual representa el 83\% del total de la estructura agraria, aunque solo controlan el $16 \%$ de las tierras aptas para cultivo (Paz, de Dios y Gutiérrez, 2014).

Las condiciones agroecológicas se caracterizan por un ambiente predominantemente semiárido. En verano son comunes las temperaturas extremas de $50^{\circ} \mathrm{C}$ y en invierno las temperaturas pueden bajar a $-5^{\circ} \mathrm{C}$. Además, las lluvias se concentran en el verano y escasean en la temporada de invierno, causando severas sequías. La provincia tiene un sistema de riego conectado a sus dos ríos principales (el Dulce y el Salado). El área de riego (región central) tiene mejores condiciones para el desarrollo agrícola y es donde la propiedad de la tierra está más regulada desde un punto de vista legal. En contraste, existe una amplia área de secano (sudoeste y noreste), caracterizada por la permanencia de los campesinos sin títulos de propiedad y es donde generalmente tienen lugar los conflictos por la tierra (Paz y Jara, 2014).

Como se puede apreciar en el cuadro 1 y el mapa 2, las ferias con mayores dimensiones se encuentran en el centro de la provincia y se caracterizan por comercializar verduras y hortalizas como rubro principal. Esto está íntimamente asociado a las mejores condiciones de producción debido al acceso al riego y la cercanía a los principales centros urbanos de la provincia: la ciudad de la Banda y Santiago Capital ${ }^{8}$.

Mapa1.

Ubicación de Santiago del Estero en el Cono Sur

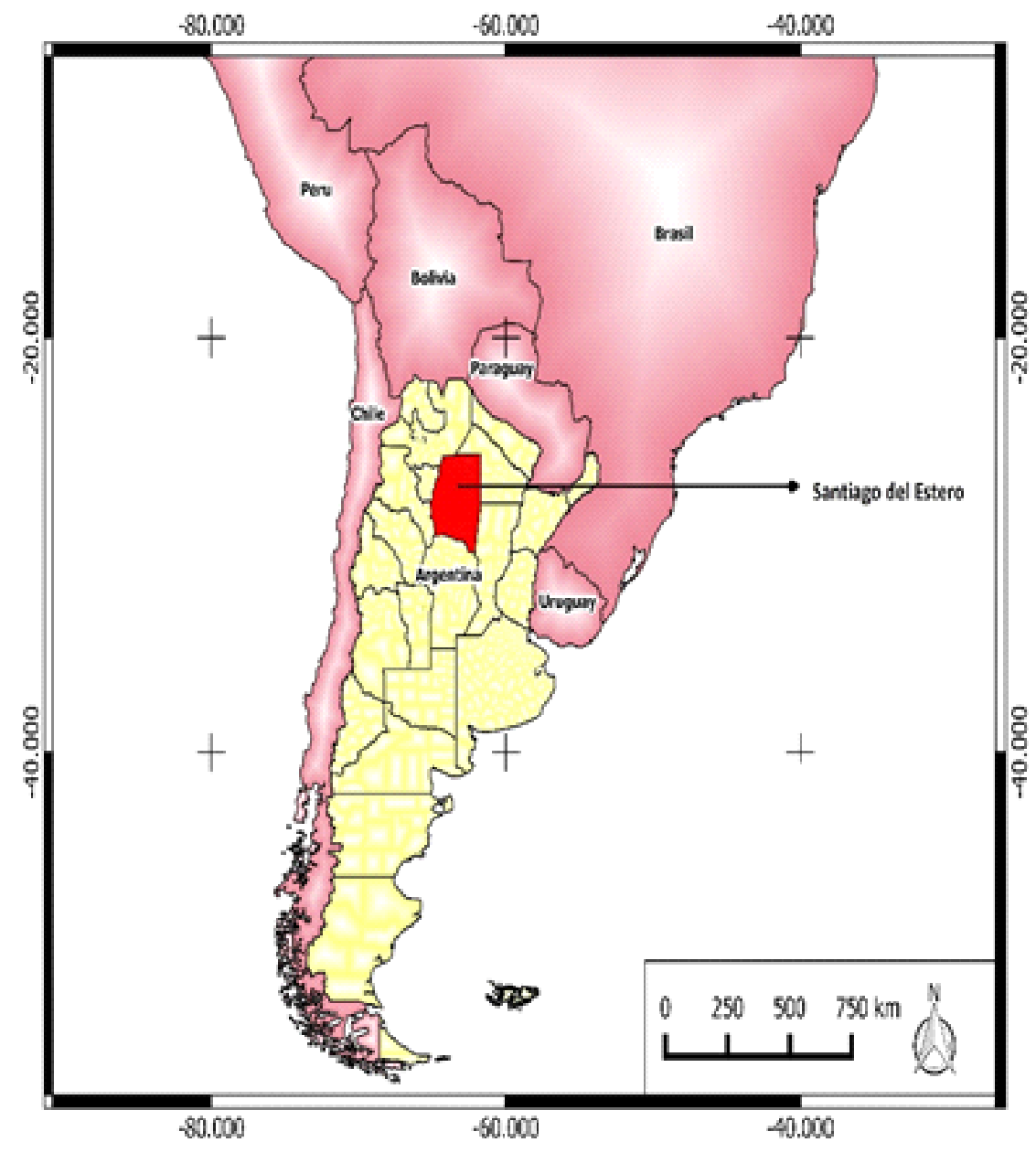

Fuente: Elaborado por Paola Marozzi, 2015 (Universidad Nacional de Santiago del Estero) 
Como se expresó antes, las primeras ferias de la agricultura familiar en Argentina surgieron a mediados de la década de 1990 en el noreste del país, las mismas representaron una reacción a la crisis de la economía regional provocada por la caída de los precios de la yerba mate y demás cultivos industriales a los que se dedicaban los pequeños productores ${ }^{9}$. El Estado Nacional las había apoyado en sus orígenes, aunque en el marco de las políticas focalizadas de contención a la pobreza (Caballero et al, 2010). Sin embargo, el desarrollo de las ferias de la agricultura familiar en Santiago del Estero es posterior a 2006, ya que desde el Estado Nacional se generaron iniciativas para promover el apoyo al sector. Tanto el Instituto Nacional de Tecnología Agropecuaria (INTA) como la Secretaría de la Agricultura Familiar (SAF) redefinieron sus estrategias de intervención donde las ferias aparecen como espacio a ser fortalecidos (Paz, Jara y Nazar, 2013).

\section{Cuadro 1.}

Ferias permanentes en la Región Centro -Oeste de la Provincias (año 2018)

\begin{tabular}{|l|l|l|l|l|l|}
\hline $\begin{array}{l}\text { Denominación de } \\
\text { la feria }\end{array}$ & Localización & Principales rubros & $\begin{array}{l}\text { Cantidad } \\
\text { de feriantes }\end{array}$ & $\begin{array}{l}\text { Estimación } \\
\text { de } \\
\text { consumidores } \\
\text { por jornada }\end{array}$ & $\begin{array}{l}\text { Frecuencia } \\
\text { de la feria }\end{array}$ \\
\hline FERISAF & La Banda & $\begin{array}{l}\text { Frutas y hortalizas, } \\
\text { huevos, quesos, pollos, } \\
\text { miel, panificados, } \\
\text { plantas. }\end{array}$ & Entre 20-25 & 400 & Semanal \\
\hline FERISAF & Capital & $\begin{array}{l}\text { Frutas y hortalizas, } \\
\text { huevos, quesos, pollos, } \\
\text { miel, panificados, } \\
\text { plantas, tejidos }\end{array}$ & Entre 20-25 & 250 & Semanal \\
\hline FERISAF & Forres & $\begin{array}{l}\text { Hortalizas, huevos, } \\
\text { quesos, dulces, } \\
\text { escabeches, pollos. }\end{array}$ & Entre 5-10 & 40 & Semanal \\
\hline Feria de la AF. & $\begin{array}{l}\text { Villa Rio } \\
\text { Hondo }\end{array}$ & $\begin{array}{l}\text { Quesos, panificados, } \\
\text { verduras, dulces. }\end{array}$ & Entre 20-25 & 60 & Mensual \\
\hline $\begin{array}{l}\text { Almacén } \\
\text { Campesino }\end{array}$ & Rio Hondo & $\begin{array}{l}\text { Quesos, panificados, } \\
\text { verduras, dulces, miel, } \\
\text { plantas medicinales, } \\
\text { derivados de harina de } \\
\text { algarroba, huevos, } \\
\text { artesanís }\end{array}$ & Entre 20-25 & 200 & Diaria \\
\hline Feria de la AF. & $\begin{array}{l}\text { Termas de } \\
\text { Rio Hondo }\end{array}$ & $\begin{array}{l}\text { Quesos, dulces, } \\
\text { panificados, miel, } \\
\text { huevos, cremas, } \\
\text { jabones, hortalizas, }\end{array}$ & Entre 15-20 & 50 & Mensual \\
\hline Progreso Familiar. & Capital & $\begin{array}{l}\text { Quesos, dulces, } \\
\text { conservas, tejidos, etc. }\end{array}$ & Entre 20 -25 & 150 & Semanal \\
\hline
\end{tabular}

Fuente: Elaborada a partir de datos proporcionada por la Subsecretaría de Agricultura de la Nación (Delegación Santiago del Estero)

La Feria Santiagueña de la Agricultura Familia (FERISAF) desde su nacimiento en 2011 está constituida por feriantes, los cuales son productores que integran el cinturón frutihortícola de la provincia. Son familias que trabajan en pequeñas parcelas (entre 2 a 10 hectáreas) y su producción es principalmente estacional. Las mismas tienen a la mano de obra familiar como el sustento de la producción y solo contratan mano de obra externa excepcionalmente. Asimismo, poseen animales para su autoconsumo y venta de excedentes.

«La venta directa sin intermediarios ha generado un impacto económico muy significativo en los pequeños productores, renovando el interés de seguir produciendo, resguardando los saberes populares y promoviendo el arraigo a la tierra, que en la actualidad es muy cotizada por ubicarse en la fertil mesopotamia santiagueña» (Entevista a técnica).

Desde sus orígenes, esta feria contó con el apoyo de agentes estatales de la SAF, INTA y Municipalidad de la ciudad de la Banda. En cuanto la estructura organizacional, se conformó una «Comisión de Feriantes», que 
recauda una cuota mínima entre los integrantes para gastos operativos. Esta comisión elaboró un reglamento donde se fijan pautas de funcionamiento, de presentación de productos, de fijación de precios y de mantenimiento de los puestos. En sus comienzos, la SAF financió la compra de estanterías, balanzas, manteles y delantales para los feriantes. Asimismo, el gobierno local otorgó un fondo de semillas hortícolas a los pequeños productores y han brindado capacitación en buenas prácticas para la manipulación de alimentos (Merlo, Gómez y Merino 2016).

\section{Mapa2. \\ Ubicación de las Ferias Permanentes en la provincia de Santiago del Estero}

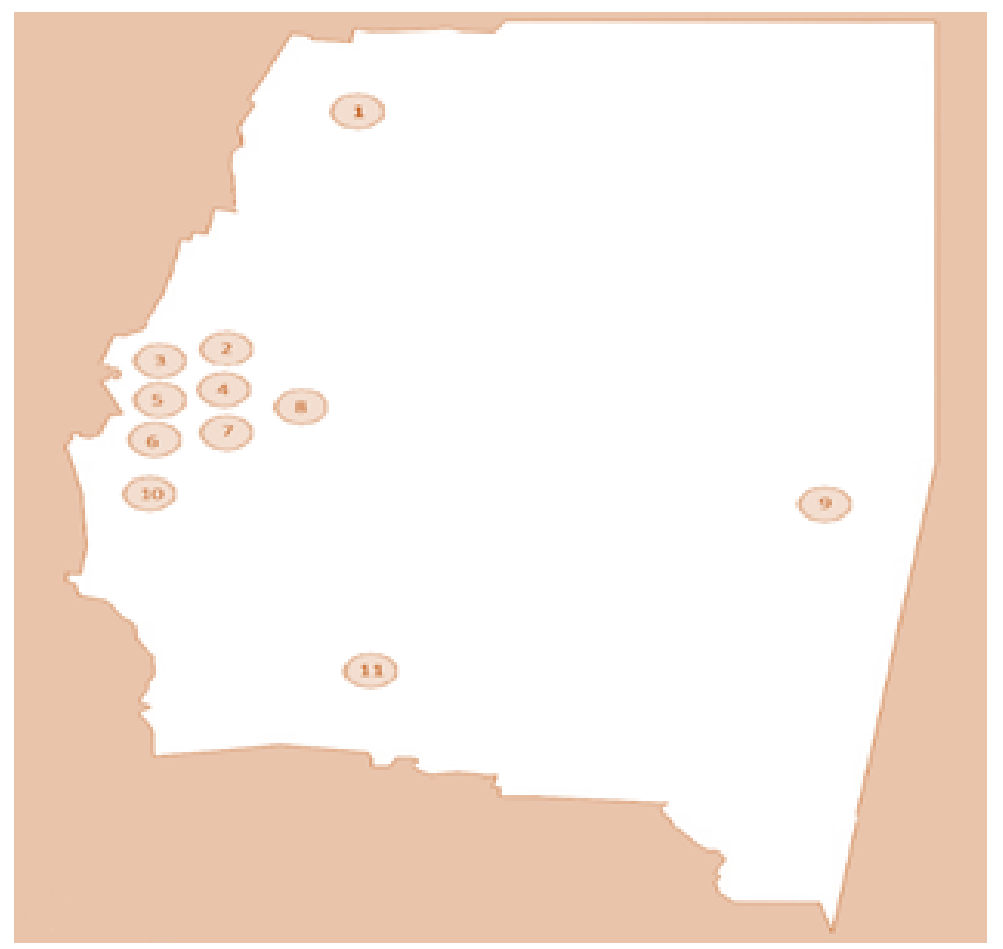

Referencias: 1) Feria Manos que Producen; 2) FERISAF Banda; 3) Almacén Campesino de Termas de Rio Hondo; 4) Feria

Progreso Familiar;5) Feria de la Agricultura Familiar de Termas; 6) Feria de Villa Río Hondo; 7) FERISAF Capital; 8)

FERISAF Forres; 9) Feria de los Juríes; 10) Feria de Villa Guasayán y 11) Feria de Ojo de Agua. Fuente: elaboración propia.

La segunda experiencia relevada se desarrolló también en la zona de riego central y se refiere al proceso organizativo del grupo «Progreso Familiar», el cual está integrado por pequeños productores de la Región Banda-Jiménez (centro-oeste de la provincia). Este grupo, que anteriormente habían sido beneficiarios del PSA (Programa Social Agropecuario) ${ }^{10}$, llegó a constituirse en asociación civil en 2016. La primera experiencia de feria tuvo lugar en el año 2011 y partir de entonces, se gestionó la realización de ferias semanales en diferentes sitios tales como la Universidad Nacional de Santiago del Estero (UNSE). La vinculación con la universidad forjó otras oportunidades de negocio, como servicios de Cáterin para eventos académicos y se han abierto canales de comercialización extra-provincial, por ejemplo, con el Mercado de Economía Solidaria Bonpland y la Expoferia Nacional de la Sustentabilidad (Suárez, Sarmiento y Corvalán, 2016).

Cabe aclarar que existen diferencias en cuanto a las estrategias de comercialización que desarrolló el grupo Progreso Familiar respecto a la FERIFAF, ya que la venta no es individual sino colectiva. Es decir, que cada familia produce en su propio predio, pero la venta es conjunta, para lo cual se conformaron pequeños grupos rotativos que asisten a la feria y se responsabilizan por la comercialización de los productos de las 25 familias involucradas. El proceso organizativo resultó bastante complejo y ha tenido que sortear diferentes conflictos, tanto entre los mismos feriantes como entre éstos y los técnicos. 
«En los comienzos, los técnicos tuvieron una amplia participación en la toma de decisiones y en la administración. Tal es así que la caja de la feria era manejada por uno de ellos. Sin embargo, el grupo fue construyendo autonomía y adquiriendo habilidades de autogestión» (Entrevista a una feriante).

Otro aspecto importante del grupo Progreso Familiar es que, por reglamento, ha logrado la unificación de los precios y se exige a los agricultores que los productos sean elaborados de forma artesanal y con recursos locales:

«Recuerdo que un cliente se quejó porque el dulce que nos compró tenía gusto a quemado. Esto nos afecta a todos porque pone en duda la calidad de nuestros productos. Por eso insistimos en mantener alto los estándares en la elaboración ya que, si no hay autocontrol de los mismos feriantes, la falta de compromiso y cuidado de uno nos afecta al resto». (Entrevista a una Feriante).

Como se puede ver en los cuadros 1 y 2, un rasgo común de todas las ferias es que, además de la venta de productos agropecuarios, se comercializan bienes que incorporan valor agregado (por ejemplo, dulces y conservas). También se destaca la oferta de servicios gastronómicos durante la realización de las ferias. Asimismo, en todas las experiencias examinadas, una de las cuestiones más conflictiva ha sido la posibilidad de reventa (principalmente de ropa y verduras adquirida en el mercado de abasto).

«fue necesario construir consenso sobre la necesidad de que los productos que se venden provengan del sector de la agricultura familiar y tomar consciencia que la feria es un complemento a la actividad productiva predial. De hecho, las prácticas de reventas de verdura no solo desvirtúan uno de los objetivos centrales de las ferias (la comercialización de la propia producción), sino que también entran en competencia y conflicto con las verdulerías aledañas» (Entrevista a técnica).

Si bien las dos iniciativas comentadas hasta el momento (FERISAF y Progreso Familiar) están ubicadas en la zona de gravitación de los principales centros urbanos de la provincia (Santiago y la Banda), también existen iniciativas de ferias emergentes en localidades más chicas y muy ligadas al espacio rural. Por ejemplo, en Villa Río Hondo se destaca la presencia de agricultores artesanos.

La misma se originó en 2006 y cuenta con un número de 20 feriantes pertenencientes a la Asociación Civil de Pequeños Productores de Rio Hondo, cuyo acompañamiento en terreno está a cargo de los Equipo del INTA y la SAF. Los encuentros de feriantes se realizan mensualmente los días sábados, con receso durante los meses de temperaturas elevadas. En este espacio, vender no es la única ni la principal actividad, pues el sentido de la práctica comprende un conjunto de razones tendientes a fortalecer los lazos de solidaridad entre los miembros, por ejemplo: se suele aprovechar el evento para realizar rifas a beneficio de los compañeros enfermos de la organización y capacitacines (Paz, Jara y Nazar, 2013).

Asimismo, los feriantes de Villa Río Hondo han desarrollado otras estrategias de comercialización, como el Almacén Campesino en la ciudad Termas de Río Hondo y han logrado constituir un fondo rotatorio de préstamos que sirve a los miembros de la organización para financiar la elaboración de los productos que se venderán luego.

Por su parte, la feria de Villa Ojo de Agua (sur de la Provincia de Santiago del Estero) inició sus actividades en 2015 con la participación de 12 feriantes. Esta experiencia recibió el apoyo interinstitucional de las agencias de desarrollo rural, el municipio, la UNSE y las radios locales. En este caso, la SAF y el INTA acompañaron la iniciativa mediante el diseño de huertas familiares y la incorporación de nuevas tecnologías (sistemas de riego por goteo, la utilización de compost para fertilizar el suelo, el control de plagas con alternativas biológicas y la diversificación de cultivos). De esta forma, se buscó mejorar la calidad de los productos elaborados por los feriantes mediante el agregado valor y el uso de buenas prácticas (la esterilización de envases para conservas, pasteurización de la leche, entre otras). 


\section{Ferias permanentes fuera de la región centro (año 2018)}

\begin{tabular}{|c|c|c|c|c|c|}
\hline Nombre & Localidad & Principales rubros & $\begin{array}{l}\text { Cantidad } \\
\text { de } \\
\text { feriantes }\end{array}$ & $\begin{array}{c}\text { Consumidores } \\
\text { por jornada }\end{array}$ & Frecuencia \\
\hline $\begin{array}{l}\text { Abriendo } \\
\text { Caminos }\end{array}$ & $\begin{array}{c}\text { Villa } \\
\text { Guasayán }\end{array}$ & $\begin{array}{l}\text { Artesanías, quesos, dulces, } \\
\text { plantas, derivados de harina } \\
\text { de algarroba, hierbas } \\
\text { medicinales, miel, huevos, } \\
\text { chacinados. }\end{array}$ & 15 & 70 & Mensual \\
\hline $\begin{array}{c}\text { Feriantes de } \\
\text { Los Juríes }\end{array}$ & Los Juríes & $\begin{array}{c}\text { Panificados, hortalizas, } \\
\text { lácteos, miel, conservas, } \\
\text { huevos, cabritos, lechones. }\end{array}$ & 15 & 100 & Semanal \\
\hline $\begin{array}{c}\text { Agricultores } \\
\text { Familiares y } \\
\text { Artesanos }\end{array}$ & $\begin{array}{l}\text { Ojo de } \\
\text { Agua }\end{array}$ & $\begin{array}{l}\text { Artesanías, quesos, dulces, } \\
\text { derivados de harina de } \\
\text { algarroba, hierbas } \\
\text { medicinales, miel, huevos, } \\
\text { flores. }\end{array}$ & 15 & 150 & Mensual \\
\hline $\begin{array}{l}\text { Manos que } \\
\text { Producen }\end{array}$ & $\begin{array}{c}\text { Nueva } \\
\text { Esperanza }\end{array}$ & $\begin{array}{l}\text { Panificados, conservas, } \\
\text { tamales, quesos, quesillo, } \\
\text { escabeches, miel, lechones, } \\
\text { cabritos, huevos, pollos, } \\
\text { verduras, artesanías. }\end{array}$ & 18 & 150 & Semanal \\
\hline
\end{tabular}

Fuente: Elaborada a partir de datos proporcionada por la Subsecretaría de Agricultura de la Nación (Delegación Santiago del Estero)

También existen ferias no permanentes de la agricultura familiar que se realizan durante fechas puntuales, como ser festividades cívicas o religiosas (la feria de Icaño, la feria de la Virgen del Pilar, la feria de Loreto, entre otras). En ellas, al igual que en las permanentes, las prácticas de trueque son habituales, pero no representan la actividad principal, ya que estos espacios de mercadeo están orientados más bien a generar un ingreso monetario extra a las familias de agricultores:

«El trueque entre compañeros suele ser una alternativa al finalizar la jornada con aquellos productos que no se pudieron vender o se los intercambia con los vecinos». (Feriante de Villa Río Hondo)

Como se puede ver en el cuadro 3, todas las ferias relevadas recibieron apoyo de la SAF, el INTA y los gobiernos locales. Sin embargo, hay que destacar que ante la falta de financiamiento por parte de la SAF desde el año 2016, las organizaciones han tenido que buscar otros canales de apoyo. Por ejemplo, el grupo Progreso Familiar gestionó ante el Gobierno Provincial un subsidio para la compra de una autoclave (aparato que permite esterilizar frascos) y un pequeño molino para hacer harina de algarroba. 


\section{Cuadro 3.}

Ferias de la agricultura familiar, organizaciones de productores participantes e instituciones de apoyo (año 2018).

\begin{tabular}{|c|c|c|c|}
\hline NOMBRE & LOCALIDAD & $\begin{array}{c}\text { TIPOS de } \\
\text { ORGANIZACIONES }\end{array}$ & $\begin{array}{c}\text { INSTITUCIONES DE } \\
\text { APOYO }\end{array}$ \\
\hline FERISAF & La Banda & $\begin{array}{c}\text { Cooperativa de } \\
\text { Productos Naturales }\end{array}$ & Municipio, SAF, INTA \\
\hline FERISAF & Capital & $\begin{array}{c}\text { Cooperativa de } \\
\text { Productos Naturales }\end{array}$ & Municipio, SAF, INTA \\
\hline FERISAF & Forres & Grupo de Feriantes & Municipio, SAF, INTA \\
\hline Feria de la AF. & Villa Rio Hondo & $\begin{array}{c}\text { Organización de } \\
\text { Pequeños Productores } \\
\text { de Rio Hondo }\end{array}$ & Municipio, SAF, INTA \\
\hline $\begin{array}{l}\text { Almacén } \\
\text { Campesino }\end{array}$ & $\begin{array}{l}\text { Termas de Rio } \\
\text { Hondo }\end{array}$ & $\begin{array}{c}\text { Grupo de asociaciones } \\
\text { Civiles zonales }\end{array}$ & Municipio, SAF, INTA \\
\hline Feria de la AF. & $\begin{array}{l}\text { Termas de Rio } \\
\text { Hondo }\end{array}$ & $\begin{array}{c}\text { Organización de } \\
\text { Pequeños Productores } \\
\text { de Rio Hondo }\end{array}$ & Municipio, SAF, INTA \\
\hline $\begin{array}{l}\text { Abriendo } \\
\text { Caminos }\end{array}$ & Villa Guasayán & $\begin{array}{l}\text { Asociación de } \\
\text { Productores }\end{array}$ & SAF, INTA \\
\hline $\begin{array}{c}\text { Feriantes de Los } \\
\text { Juríes }\end{array}$ & Los Juríes & Sociedad de Hecho & Municipio, SAF, INTA \\
\hline $\begin{array}{l}\text { Agricultores } \\
\text { Familiares y } \\
\text { Artesanos }\end{array}$ & Ojo de Agua & Grupo de productores & Municipio, SAF, INTA \\
\hline $\begin{array}{l}\text { Progreso } \\
\text { Familiar }\end{array}$ & Capital & Asociación civil & $\begin{array}{l}\text { UNSE, Municipio, SAF, } \\
\text { INTA }\end{array}$ \\
\hline $\begin{array}{l}\text { Manos que } \\
\text { Producen }\end{array}$ & Nueva Esperanza & $\begin{array}{c}\text { Organización de } \\
\text { Hecho }\end{array}$ & Municipio, SAF, INTA \\
\hline
\end{tabular}

Fuente: Elaborada a partir de datos proporcionada por la Subsecretaría de Agricultura de la Nación (Delegación Santiago del Estero)

Otro aspecto a destacar de las ferias es el papel protagónico de las mujeres. Una artesana tejedora resalta que: «los hombres son más tímidos para vender. Ellos van y nos ayudan a poner las cosas, pero no se quedan. Las mujeres tenemos más iniciativas para la venta». Cabe destacar que la participación de las mujeres en las ferias constituye una práctica usual que se debe a múltiples factores. Por un lado, hay que señalar que Santiago del Estero se caracteriza por contar con una población rural compuesta por trabajadores del sector agropecuario que migran hacia otras provincias mientras que, generalmente, son las mujeres quienes se quedan cuidando el hogar, los animales, las plantaciones y también garantizan la participación asidua en las organizaciones de base (espacio desde donde se impulsaron las ferias). Por otro lado, son estas mismas organizaciones de bases, desde donde se han implementado diferentes cursos de capacitación en cuestiones no solo productivas sino también de género, promoviendo espacios de participación femenina y un mayor empoderamiento de las mujeres (Tort y Nazar, 2016).

Habiendo presentado una rápida descripción de las ferias que existen a lo largo y ancho del territorio provincial, se intenta examinar seguidamente cierta fortalezas y debilidades en torno a las mismas. 


\section{Potencialidades emergentes de las ferias de la agricultura familiar}

Actualmente, uno de los principales obstáculos para la expansión y consolidación de las ferias lo constituye la pérdida del apoyo técnico y financiero que recibían del Estado Nacional. Lo cual implica serias limitaciones para el desarrollo de las ferias en particular. Más aún, si se toma en cuenta que estas iniciativas, al menos en el caso de Santiago del Estero, surgen con un fuerte impulso por parte de las políticas públicas.

A pesar de aquellas dificultades coyunturales, la investigación empírica permite identificar algunas potencialidades de las ferias de la agricultura familiar que las convierten en brotes o semillas de un modelo de desarrollo rural alternativo.

En primer lugar, las ferias constituyen parte de las estrategias de los pequeños productores tendientes a lograr la colocación regular de la producción y la generación de un ingreso alternativo. Para lo cual, apelan a la diversificación de sus producciones, a la artesanalidad, a la incorporación de valor agregado y al uso de recursos locales (endogeneidad). En efecto, estas características permiten ampliar los márgenes de autonomía para decir qué producir, a qué precio y a quién vender.

Como lo expresan Hebinck, Schneider y Van Der Ploeg (2015), los mercados siempre han sido escenarios importantes para las luchas rurales, pero esas luchas usualmente se habían centrado en la renegociación de los términos de intercambio. El mercado como tal se dio por hecho. Sin embargo, lo que está ocurriendo en el campo va más allá de la búsqueda de mejoras en los mercados, implica la creación de nuevos canales de comercialización.

En otras palabras, el desarrollo de las ferias está ligado a la construcción de circuitos cortos entre productores y consumidores (cara a cara) para reducir el número de intermediario. Asimismo, las ferias se orientan principalmente al consumo local y se desarrollan en las cercanías de sus explotaciones, sirviendo al abastecimiento de las poblaciones aledañas (Suárez y Paz, 2015; Rodríguez Sperat, Paz, Suárez y Díaz, 2015).

Las ferias comprenden una reivindicación de las prácticas agroecológicas, ya sea por su forma tradicional de producir vinculada la racionalidad ecológica campesina (Toledo, 1993) o porque han recibido asesoramiento técnico. A partir del trabajo de campo se puede inducir que en ellas se promueve una mayor conciencia de la necesidad de producir alimentos sanos a partir de lógicas no depredadora del medioambiente. Pese a que las ferias no cuentan aún con certificación agroecológica de sus productos, constituyen espacios para un acceso popular a alimentos de calidad.

Por otro lado, las ferias de la agricultura familiar promueven la reciprocidad, lo cual difiere de los imperativos del mercado, como ser la competencia y la maximización de ganancias ilimitada (Suárez y Paz, 2015). En otras palabras, las ferias para su formación y funcionamiento requieren de la cooperación. Por tanto, no son simplemente un segmento de ventas al por menor tendiente a mejorar la posición de negociación que adquieren los productores-feriantes, sino que también representan un espacio público donde se despliegan lazos de solidaridad y participación entre los diversos actores (Dos Anjos, Godoy y Caldas, 2005).

Las distintas experiencias de ferias surgen en la interface con otros actores (Hebinck, Schneider y Van Der Ploeg, 2015) es decir, que constituyen espacios que se desarrollan al amparo de una red entre productores, feriantes y agentes estatales. El apoyo de los gobiernos es variable. Algunos municipios sólo habilitan el espacio de venta, mientras que otros asisten el proceso organizativo, colaborando en la resolución de los problemas que van surgiendo (Golsberg et al, 2010)

Asimismo, las ferias son espacios de socialización, puesto que usualmente la compra y venta se complementa con espectáculos musicales y juegos. Las ferias son siempre una oportunidad de encuentro entre compañeros de la organización, técnicos y autoridades locales (Paz, Jara y Nazar, 2013).

En suma, las ferias de la agricultura familiar tienen una dimensión política central: son una expresión de las luchas cotidianas que actualmente caracterizan al campo. Inicialmente, los actores que participan probable- 
mente no consideran sus acciones como políticas, no obstante, mientras comercializan, pueden construir otras formas de poder basada en la cooperación (Tria Kerkvliet, 2009).

En esta misma dirección, el creciente protagonismo de las mujeres en las experiencias mencionadas ha convertido a las ferias en un espacio por excelencia desde donde disputar con los relatos que las confinan exclusivamente al espacio doméstico. Esto ha impuesto nuevas dinámicas en las que las mujeres de la agricultura familiar han ganado espacios de protagonismo.

\section{Conclusión}

La promoción de la agricultura familiar es un tema que goza de consenso internacional por su aporte a la provisión de alimentos, a la gestión de la biodiversidad y a la superación de la pobreza (FAO, 2018). Sin embargo, existen serias dificultades del sector para articular con un sistema agroalimentario altamente concentrado que se caracteriza por el rol de los supermercados como principales centros de abastecimiento y las grandes distancias entre la localización física de la producción y los consumidores, quienes usualmente desconocen el origen de los alimentos que consumen (Rodríguez Sperat, Paz, Suárez y Díaz, 2015).

Frente a esta situación, las ferias de la agricultura familiar en Santiago del Estero buscan vincular directamente producción y consumo mediante la venta directa de productos frescos. Los resultados de la investigación permitieron identificar fortalezas y desafíos para la consolidación de las ferias. También es posible extraer algunas reflexiones con miras a una eventual reorientación de las políticas públicas hacia el sector.

En primer lugar, se observa que cuando recibieron apoyo del gobierno (2006-2015), las ferias lograron avanzar en aspectos estrictamente comerciales (por ejemplo: acondicionamiento del lugar, gestiones de permisos por parte de organismos público para la instalación de los puestos y marketing). Sin embargo, las políticas públicas deberían mirar más a fondo qué hay detrás de la construcción de estas prácticas de mercadeo para poder consolidar a las ferias. Esto conlleva la necesidad de fortalecer ciertas lógicas que forman parte del estilo de producción de la agricultura familiar tales como la intensificación de la mano de obra familiar, la diversificación de la producción, la utilización de recursos endógenos, el agregado de valor y la artesanalidad (Hebinck, Schneider y Van Der Ploeg (2015).

Estas estrategias productivas, complementadas con la participación en las ferias, dan cuenta de una lucha por ampliar los márgenes de maniobra de los productores. Lo cual implica una dinámica de contracción y expansión a partir de decisiones comerciales concretas que procuran controlar la organización de su propio trabajo mediante canales de venta mucho más flexibles, rápidos y directos.

Pese a los recortes presupuestarios por parte del Estado Nacional que se aplicaron entre 2015-2018, las redes que se han tejido en años anteriores entre feriantes, agentes estatales (muchos de ellos despedidos por el gobierno de Macri), universitarios y consumidores locales han contribuido a dar continuidad a las experiencias. No obstante, en la medida que las políticas públicas no acompañen estos procesos, al menos es su etapa embrionaria, corren el riesgo de convertirse en una puesta en escena de un espectáculo folclorizado, pero sin un impacto real en la mejora de las vidas de los productores rurales. Es decir, en brotes marchitos.

Asimismo, lo significativo del anclaje empírico del artículo en relación al marco teórico consiste en que, usualmente, los estudios sobre la agricultura familiar se centraron en su posición de desventajas frente al control ejercido por los grupos agroindustriales. Sin embargo, la perspectiva que se adoptó en este artículo, basada en una hermenéutica de la emergencia, se orienta a un campo de interés diferente: más que describir la situación de marginalidad estructural de los pequeños productores frente a los mercados, el propósito fue captar su capacidad de agencia para revertir aquella situación e identificar en las experiencias en marcha potencialidades orientadas a la construcción de un modelo de desarrollo alternativo.

Asimismo, el artículo trató de demostrar que esas potencialidades de las ferias están más allá de lo comercial: son espacios de construcción de ciudadanía, lo que se puede ver en el rol protagónico que van 
cobrando las mujeres feriantes y en las mismas prácticas de cooperación que requieren las ferias para ponerse en funcionamiento. Todo ello no sería posible sin las sinergias que allí se despliegan.

\title{
Notas
}

\begin{abstract}
${ }^{1}$ En diciembre de 2015, asumió la Presidencia de la República Mauricio Macri. Durante las primeras semanas de su gobierno se tomaron medidas favorables al sector agroexportador (eliminación de derechos de exportación al trigo y al maíz, liberalización del mercado cambiario y desregulación comercial), en desmedro del sector de pequeños y medianos productores (por ejemplo, recortes en el programa Cambio Rural que daba asistencia técnica a pequeños productores). Posteriormente, se puso en marcha un plan de ajuste fiscal que implicó, entre otras medidas, el despido masivo de técnicos de la Secretaría de Agricultura Familiar. A ello se suma la creciente inflación que se tradujo en reducción del poder adquisitivos de los ingresos laborales y no laborales.
\end{abstract}

${ }^{2}$ En un artículo de la BBC News (04/09/2018), se revela que Argentina produce comida para 440 millones de personas. Por lo tanto, podría alimentar 10 veces su población. Este país sudamericano es el tercer productor mundial de miel, soja y limones; el cuarto de maíz y carne; el quinto de manzanas; el séptimo de trigo y aceites.

${ }^{3}$ Entre los hechos más significativos de este período se puede mencionar la creación del Foro Nacional de la Agricultura Familiar (FONAF), en agosto del 2006, con la participación de representantes de numerosas organizaciones del campo, que generó los lineamientos sobre políticas públicas diferenciadas para el sector. Luego, en 2009, se creó la Secretaría de Agricultura familiar.

${ }^{4}$ Para Stuiver y Wiskerke (2004) las novedades son diferentes de las innovaciones. Para estos autores, las innovaciones son lineales y creadas en el sistema científico, las cuales son transferidas luego a otro espacio en el que son replicadas, adaptadas o mejoradas. En cambio, las novedades se relacionan con un saber práctico, representan rupturas constantes a lo largo de un proceso discontinuo e imprevisible que se hace en todo momento.

${ }^{5}$ Anteriormente, el sociólogo alemán Niklas Luhmann había planteado una idea similar, señalando que el fin del conocimiento social es «hacer comprensible la acción como posibilidad» (1973: 40). Por tanto, se trataría del estudio de la sociedad con el propósito de dar cuenta de las posibilidades creativas y no de leyes universales e inmutables.

${ }^{6}$ Para Long (2007), las situaciones de interfaces se refieren a puntos de intersección entre diferentes sistemas sociales o arenas. Así, la presencia de actores diversos implica una conjunción - confrontación de visiones, una batalla de conocimientos, donde se expresan estrategias y objetivos muy diversos en torno al concepto de desarrollo rural.

${ }^{7}$ Según el Censo Nacional de Población de 2010, Santiago del Estero tenía un 31\% de población rural, frente a un 3\% de Buenos Aires o un $10 \%$ de la provincia de Córdoba.

${ }^{8}$ Según datos del Censo Nacional de Población 2010, la ciudad de Santiago del Estero tiene 252.192 habitantes y la Banda 95.000 habitantes.

${ }^{9}$ Una de las ferias más grandes es la de Oberá (provincia de Misiones), nacida en 1995, que cuenta con personería jurídica, con reglamento interno de funcionamiento y con una Comisión Directiva elegida por sus asociados. Su surgimiento fue el resultado de la convergencia de distintos actores: el Movimiento Agrario Misionero (MAM), la Pastoral Social y diferentes organizaciones no gubernamentales que acompañaron su conformación.

${ }^{10}$ En década de 1990, se implementaron programas dirigidos a los pobres rurales, entre ellos el Programa Social Agropecuario. Originalmente, este tipo de programa tuvo un perfil asistencialista y de contención de la pobreza en un contexto de aplicación de políticas macroeconómicas de corte neoliberal por parte de los gobiernos menemistas (1989-1999) que conllevaron una reducción sustancial de la cobertura de los programas de crédito, asistencia técnica y comercialización a los pequeños productores.

\section{Bibliografía}

BBC News (2018). «Por qué hay hambre en Argentina si se produce comida para 440 millones de personas». Artículo periodístico publicado el 4 septiembre 2018. Recuperado de https://www.bbc.com/mundo/noticiasamerica-latina-45303359

Caballero, L. et al (2010). Los procesos organizativos de la agricultura familiar y la creación de ferias y mercados de economía social. Otra Economía 4(7). Recuperado de: www.riless.org/otraeconomia

Carvalho, C. et al (2014). Bases teóricas e metodológicas: A trajetória, os desafios e o aprendizado de uma pesquisa 
comparada. En S. Schneider, M. Menezes, A.G. Silva, e I, Bezerra. (2014). Sementes e Brotos da Transição, (pp. 27-49). Porto Alegre, Brasil: Universidad Federal de Rio Grande del Sur

CEPAL (2013). Agricultura familiar y circuitos cortos. Nuevos esquemas de producción, comercialización y nutrición. Serie de Seminarios y Conferencias. Santiago, Chile: Cepal.

De la Garza, E. (2001). La epistemología crítica y el concepto de configuración. Revista Mexicana de Sociología. 63(1), 109-127.

De Sousa Santos, B. y Rodríguez, C. (2011). Para ampliar el canon de la producción. En B. De Sousa Santos, (comp). Producir para vivir: los caminos de la producción no capitalista (pp.15-61). Ciudad de México, México: Fondo de Cultura Económica.

Dos Anjos, F., Godoy, W. y Caldas, N. (2005). As Férias livres de Pelotas sob o imperio da globalização: perspectivas e tendencias. Pelotas, Brasil: Editora e Gráfica Universitária.

FAO (2018). Panorama de Seguridad Alimentaria y Nutricional en América Latina y el Caribe 2018, Santiago, Chile: FAO. Recuperado de: http://www.fao.org/3/CA2127ES/CA2127ES.pdf.

Elver, H. (2019). Informe de la Relatora Especial sobre el derecho a la alimentación en la Argentina. Ginebra, Suiza: Consejo de Derechos Humanos de la ONU

Fernándes, B. M. (2009). Territorios teoría y política. En J.M. Medina y F. Lozano. Las configuraciones de los territorios rurales en el siglo XXI (pp. 35-66). Bogotá, Colombia: Editorial Pontificia Universidad Javeriana.

FONAF (2006). Documento elaborado por las Organizaciones representativas del sector productor agropecuario familiar. Mendoza, Argentina: SAGPyA, PRODERNOA.

García, A. y Fontanet, F. (2018). Políticas públicas dirigidas a la Economía Social y Solidaria. Tensiones, alcances y desafíos en la experiencia de San Martín (Argentina, 2016-2017). Revista Vasca de Economía Social, 14 (15). DOI: $10.1387 /$ reves.20519

Golsberg, C. et. al (2010). Agricultura Familiar: ferias de la Agricultura Familiar en la Argentina. Buenos Aires, Argentina: Ediciones INTA.

Hebinck, P., Schneider, S. y Van Der Ploeg, J.D. (2015). Rural development and the construction of new markets. Londres, Inglaterra: Routledge.

Long, N. (2007). Sociología del Desarrollo: Una perspectiva centrada en el actor. Ciudad de México, México: El Colegio de San Luis-CIESAS.

Luhmann, N. (1973). Ilustración sociológica y otros ensayos. Buenos Aires, Argentina: Sur.

Mc Michael, P. (2013). Food regimes and agrarian questions. Agrarian Change and Peasant Studies Series, 3.

Merlo, M., Gómez, V., y Merino, A. C. (2016). Estrategias de Comercialización de la Agricultura Familiar: Ferisaf. En M. Gutiérrez y V. González. (comp.) Desarrollo Rural, Políticas Públicas y Agricultura Familiar (pp.151174). Tucumán, Argentina: Editorial Magna. I

Paz R., Jara, C. y Nazar, P. (2013). Economía Social y Agricultura Familiar. La experiencia de la Feria de Villa Río Hondo (Argentina). Cayapa. Revista Venezolana de Economía Social 13 (25)

Paz, R., y Jara, C. (2014). Estructura agraria en Santiago del Estero: el proceso de territorialización de las explotaciones campesinas sin límites y su tensión frente al avance del capitalismo agrario. Estudios Rurales. Publica- 
ción del Centro de Estudios de la Argentina Rural 1(6), 81-99.

Paz, R., De Dios, R., y Gutiérrez, M. (2014). La agricultura familiar en Santiago del Estero. Cuantificación y análisis a partir de los datos del Registro Nacional de la Agricultura Familiar. Tucumán, Argentina: Magna.

Rodríguez, R., Paz, R., Suárez, V., y Díaz, J. P. (2015). Construyendo mercados desde la propia finca: tres experiencias sobre circuitos cortos en la agricultura familiar. Revista Agro Sur, 43(1). DOI:10.4206/ agrosur.2015.v43n1-02

Schneider S., Menezes M., Silva A. G., Bezerra I. (2014). Sementes e Brotos da Transição. Porto Alegre, Brasil: Universidad Federal de Rio Grande del Sur

Schneider, S. y Menezes, M. (2014). Inovação e atores sociais. S. Schneider, et al. Sementes e Brotos da Transição (pp 13-27. Porto Alegre, Brasil: Universidad Federal de Rio Grande del Sur

Stuiver, M. y Wiskerke, J. (2004). The VEL and VANLA enviromental co operatives as a niche for sustainable development. In J.S.C. Wiskerke, \& J.D. Van der Ploeg (eds.). Seeds of transition: essays on novelty production, niches and regimes in agriculture (pp. 119 148). Assen, The Netherlands: Royal Van Gorcum

Suárez, M.V., y Paz, R. (2017). Pensando los procesos de acumulación en sistemas comunales: desarrollo de las fuerzas productivas, innovaciones tecnológicas y Estado. El caso de Colonia Jaime, Argentina / Eutopía. Revista de Desarrollo Económico Territorial. (11), 97-112. DOI: https://doi.org/10.17141/eutopia.11.2017.2655

Suárez, M.V, Sarmiento, R. y Corvalán, S. (2016). Las ferias como circuito corto de comercialización en la Agricultura Familiar. El caso del grupo Progreso Familiar. M. Gutiérrez y V. González. (comp.) Desarrollo Rural, Políticas Públicas y Agricultura Familiar (pp. 135-150). Tucumán, Argentina: Editorial Magna.

Toledo, V. M. (1993). La racionalidad ecológica de la producción campesina. En Ecología, campesinado e historia (pp. 197-218). Buenos Aires, Argentina: La piqueta.

Tort, J. y Nazar P. (2016). Hacia un empoderamiento económico y social. La experiencia de las mujeres en la feria de Rio Hondo. En M. Gutiérrez y V. González. (comp.) Desarrollo Rural, Políticas Públicas y Agricultura Familiar (pp. 175-195). Tucumán, Argentina: Editorial Magna.

Tria Kerkvliet, B. (2009). Everyday politics in peasant societies (and ours). The journal of peasant studies, 36(1), 227-243.

Vasilachis, I. (2006). Estrategias de investigación cualitativa, Buenos Aires, Argentina: Gedisa.

Wiskerke, J. (2004). Seeds of Transition: essays on novelty production, niches and regimes in agriculture. Assen, The Netherlands: Royal van Gorcum. 